\title{
Cien años de la reforma: claves para analizar la actualidad de la universidad argentina
}

One hundred years of university reform: keys to analyse the present of the argentinian university

\author{
Enzo Andres Scargiali scargiali@gmail.com \\ http://orcid.org/0000-0002-1963-5597
}

Instituto de Estudios de América y el Caribe; Facultad de Ciencias Sociales; Grupo de Estudios de Sociología Histórica de América Latina; Universidad de Buenos Aires (Argentina)

\section{Resumen}

La reseña analiza el libro Reforma Universitaria y conflicto social, 1918-2018 de Eduardo Díaz de Guijarro y Martha Linares, editado por Batalla de Ideas en octubre de 2018. La obra se divide en dos grandes secciones. En la primera, se analiza la relación entre movimiento estudiantil y sindicalismo, en tanto que la segunda, traza un puente entre la reforma universitaria de 1918 y la actualidad del sistema de educación superior y ciencia y tecnología. Finalmente, se realiza una breve reflexión acerca del texto. 
Palabras clave: Reforma universitaria; movimiento obrero; conflicto social; universidad; ciencia y tecnología.

\section{Abstract}

The review analyzes the book University Reform and Social Conflict, 1918-2018 by Eduardo Díaz de Guijarro and Martha Linares, published by Batalla de Ideas in October 2018. The work is divided into two large sections. In the first, the autors analyze the relationship between the student movement and unionism, while the second, draws a bridge between the university reform of 1918 and the present of the system of higher education and science and technology. Finally, a brief reflection about the text is made.

Keywords: University reform; unionism; social conflicto; university; science and technology.

Reforma Universitaria y conflicto social, 1918-2018 de Eduardo Díaz de Guijarro y Martha Linares, editado por Batalla de Ideas en octubre de 2018, propone una nueva mirada sobre la relación entre educación superior y la sociedad. En este sentido, se centran en demostrar que las movilizaciones estudiantiles de 1918 eran parte de un ciclo de protestas cuyo principal protagonista era la clase obrera, posicionada en contra de la oligarquía local. Para ello recurren a una sólida investigación bibliográfica y reúnen material historiográfico, fuentes primarias, diarios de la época, fotografías y testimonios de protagonistas.

Mientras que en los primeros capítulos del libro demuestran la forma en que la oligarquía de la provincia de Córdoba actuaba frente al sistema universitario, en la segunda parte, se centran en describir el modo en que la concentración económica, política e ideológica se funde en manos de la burguesía dominante de la actualidad.

El Capítulo I, "Un nuevo enfoque sobre la Reforma de 1918", analiza la relación entre movimiento obrero y estudiantil contra los sectores dominantes cordobeses. Busca dar comprensión sobre las limitaciones posteriores a la Reforma, en tanto que el reflujo de las luchas sociales impidió la profundización de las transformaciones de las universidades.

Mientras que los textos clásicos respecto de este proceso se han centrado en describir una batalla cultural entre estudiantes y profesores, dogmáticos y acientíficos- y como logran romper con el clericalismo en la educación superior, el libro indaga en la relación entre el movimiento estudiantil cordobés y los sindicatos obreros y las luchas de los trabajadores. En este marco, Díaz de Guijarro y Linares sostienen que la bibliografía clásica respecto de la temática ha 
invisibilizado el rol que el movimiento obrero tuvo durante el desarrollo del conflicto, y la unidad entre ambos sectores. Además, destacan que existe evidencia respecto de la relación entre los miembros del gobierno provincial y los dirigentes de las empresas patronales y las camarillas clericales, por lo que obreros y estudiantes se enfrentaban a un enemigo común. Los autores, en este sentido, sostienen que la Reforma se encontraba inserta en un conflicto de mayores proporciones en el que confluyeron diferentes sectores sociales con los universitarios que se enfrentaban a la clase dominante provincial.

A lo largo del Capítulo II, "La oligarquía y el capitalismo cordobés", los autores describen el contexto político, económico y social que se desarrollaba en la provincia de Córdoba desde finales del siglo XIX, en que destacan la fuerte relación que existía entre los miembros de la oligarquía local con el sector comerciantes y la Iglesia.

Por último, hacen referencia a la sanción de la Ley Sáenz Peña en 1912 donde los autores coinciden que a pesar de los cambios en el sistema político nacional, en que en las vísperas de la Reforma de 1918, el sector clerical continuaba siendo predominante en el gobierno provincial y en la universidad.

"El movimiento obrero" es el capítulo III, que se centra en las características del movimiento obrero cordobés: la defensa del salario, la estabilidad laboral, la reducción de las jornadas laborales, mejores condiciones de salubridad y reconocimiento de sus organizaciones sindicales. En 1917, frente a un periodo de reactivación económica con demanda de empleo, comenzaron a producirse nuevas luchas obreras, que coincidieron con el crecimiento de los sectores medios y su demanda por acceso a educación, lo que nos conduce al Capítulo IV: "La reforma universitaria". Siempre haciendo referencia al caso de la Universidad Nacional de Córdoba (UNC), Díaz de Guijarro y Linares destacan que los estudiantes objetaban no sólo la organización de la dirección de la casa de estudios sino, principalmente, las concepciones dominantes sobre la ciencia y la cultura que defendían los sectores católicos del cuerpo profesoral.

En 1918 las clases no comenzaron en la UNC. Con la primera huelga general, del 14 de marzo, sobrevino el cierre e intervención de la institución. En este punto, los autores relativizan el peso que tenía el reclamo por la "autonomía universitaria" ya que consideran que a pesar de que reclamaban el fin de los cargos vitalicios, a la vez, solicitaban la intervención del Poder Ejecutivo Nacional.

En efecto, a partir de un recorrido por los puntos más álgidos del conflicto, los autores logran reunir diferentes evidencias que les permiten afirmar que el accionar de los estudiantes fue más que una batalla académica, puesto que se daba en el marco de un clima de agitación obrera general contra un enemigo en común: la oligarquía cordobesa. 
En el Capítulo V: ¿Qué estuvo en juego en 1918?” Díaz de Guijarro y Linares realizan un pormenorizado análisis de los principales intereses y concepciones políticas y sociales que la Reforma puso en juego. En primer lugar enfatizan que los conflictos laborales no disminuyeron y que por otro lado, los sectores conservadores incrementaron sus acciones violentas en pos de recuperar su influencia. También, brindan espacio a la expansión de las luchas sociales, con epicentro en Córdoba y hacia el resto del país haciendo hincapié en las manifestaciones desarrolladas por mujeres movilizadas, en las luchas obreras y en la universidad.

A lo largo del Capítulo VI, "La reforma continental", Díaz de Guijarro y Linares se centran en examinar los antecedentes y repercusiones a nivel continental de la Reforma. Aquí, ponen en discusión las posiciones antagónicas de las implicancias de política de la Reforma: la postura de Raúl Haya de la Torre en Perú, centrada en el papel de la juventud como vanguardia política enmarcada en una postura antiimperialista pero de colaboración de clases; y la de Antonio Mella, en Cuba, quien sostenía que la vanguardia del cambio social debía ser la clase trabajadora, acompañada por estudiantes y la juventud.

Los Capítulos VII, "A cien años del conflicto cordobés" y VIII, "El neoliberalismo en el poder" fueron pensados por los autores como un puente entre el relato histórico del conflicto y la coyuntura actual del sistema de educación superior.

En este contexto, realizan un recorrido por los conflictos políticos, sociales y económicos que atravesaron desde la década de 1930 -con la inauguración del primer golpe de Estado- hasta la expansión y crisis del neoliberalismo durante la década de 1990 y las características de la estructura del gobierno de Mauricio Macri a partir de 2015.

En este marco, el Capítulo IX, "Universidad, ciencia y tecnología en el neoliberalismo" es un profundo ejercicio de reflexión en el que los autores hacen un recorrido por la transformación de las políticas de Estado en este ámbito: desde la reducción del presupuesto hasta los planes de mercantilización de la educación superior. Por otro lado, realizan un resumen de los principales conflictos encabezados por científicos y docentes frente al neoliberalismo.

Por último, el Capítulo X, "Una nueva universidad para una sociedad más justa" abreva en las fortalezas y debilidades que el sistema universitario afronta actualmente: el papel de la integración latinoamericana; la proyección social de la educación superior; la pedagogía -en el marco de la consideración de la educación como un bien social, un derecho humano y universal-; la formación de profesionales comprometidos con la sociedad; la investigación científica, al servicio del desarrollo y la resolución del problemáticas sociales; la extensión, uno de los ejes de la Reforma, para la difusión de la cultura y la participación ciudadana.

Díaz de Guijarro y Linares, a lo largo de las páginas de "Reforma universitaria y conflicto social, 1918-2018" logran sus objetivos demostrando cómo el sistema universitario, en 1918 y

Question, Vol. 1, N. ${ }^{\circ}$ 63, julio-septiembre 2019. ISSN 1669-6581

Instituto de Investigaciones en Comunicación | Facultad de Periodismo y Comunicación Social | Universidad Nacional de La Plata La Plata | Buenos Aires | Argentina

Página 4 de 5 
actualmente, ha sido un campo de disputa entre modelos políticos, sociales y económicos que no se encuentra desligado de otros sectores de la sociedad, como las organizaciones de trabajadores y el movimiento de mujeres. En este sentido, concluyen afirmando que "las batallas que se producen dentro de las universidades no son sólo educativas o culturales. Son también batallas sociales, políticas y económicas, y forman parte de los conflictos de la sociedad en su conjunto" (p. 162).

\section{Bibliografía}

Díaz de Guijarro, E. y Linares, M. (2018). Reforma universitaria y conflicto social, 1918-2018. Buenos Aires: Batalla de ideas. 